\title{
Meeting the challenges - year 2010 and beyond
}

\author{
Kamani Wanigasuriya ${ }^{1}$ \\ Journal of the Ceylon College of Physicians, 2010, 41, 40-46
}

It is with great respect and profound feeling of humility that I accept the Presidency of the Ceylon College of Physicians. As I stand here, I am well aware of the history of our College which spans over 40 years and I feel privileged to be listed alongside my illustrious predecessors. They were outstanding clinicians and academics who made significant contributions to the medical profession of this country. I will do my best to carry out my duties as President and uphold all the noble values the College stands for.

The Ceylon College of Physicians was established in 1967. During its long and prestigious history, the College has maintained its distinguished tradition of educating its members, postgraduate trainees and other health care professionals in Sri Lanka. The annual conference, lectures, and training courses organised by the College have been the cornerstone of medical education for the younger generation. The College recognises the achievements of its members by awarding fellowships and awards and takes an active interest in matters related to the health policy and in administrative matters related to its membership.

Medicine has come a long way since the time of Hippocrates of ancient Greece. Though Gods dominated their lives, Greek physicians from as far back as $1200 \mathrm{BC}$ tried to find a natural explanation as to why persons became ill and died. Health care around 1880 was principally about "disease control" followed by the concept of "health promotion" in the 1920's. In the 1960's, management of non-communicable diseases took centre stage as it was the era of social engineering. Since 1981 "health for all" is the aim of health services worldwide. Practice of medicine in Sri Lanka dates way back to the era of kings and kingdoms. There were established hospitals in our ancient kingdoms of Anuradhapura and Polonnaruwa. Western medicine was introduced to the country during Portuguese (1505) and Dutch occupation (1656). A new era was entered into when the British created the Civil Medical Department in 1858, which enabled civilians to obtain health care, free of charge. Since then, many

\footnotetext{
${ }^{1}$ Senior Lecturer in Medicine and Head Department of Medicine, University of Sri Jayewardenepura. President, Ceylon College of Physicians 2010.
}

developments have taken place and today Sri Lanka is a country with a proud list of achievements in health care.

Today with the dawn of year 2010 we are rapidly progressing ahead. The practice of medicine has changed dramatically during the last few decades. Recent advances in biomedical research, medical technologies, the changing demography of the population, escalating costs of health care and public expectations has created a major impact on the way medicine is practiced. It is wise for us as physicians to look ahead and rise up to the challenges faced by us in this new era. Therefore the induction address today will focus on 'meeting the challenges - year 2010 and beyond'.

A physician is a person skilled in the art of healing, specifically one who is educated, clinically experienced, and licensed to practice medicine as usually distinguished from surgery.

Merriam-Webster Dictionary

The main role of a consultant physician is to provide efficient and compassionate care for the patient. The ability to make a clinical judgment is a unique skill of a physician. Development of this skill needs thorough learning and experience gained over many years. The other commitments of a physician include medical education, serving in educational boards, developing specialty areas, engaging in research and ensuring continuous professional development.

\section{The physician workforce in Sri Lanka}

During the British era, the General Hospital in Colombo was built at Longden Place which was later renamed as Kynsey Road and opened in 1864. Subsequently physicians were appointed and the profession started to progress. Many of the physicians who held positions in early days have contributed enormously to the development of the medical profession in Sri Lanka.

Our own history is now over 100 years old. What is the present and the future? The total number of physicians currently serving in state sector hospitals is 146 according to the 2009 statistics of the Ministry of Health. This includes consultant physicians, 
resident physicians and OPD physicians attached to the Ministry of Health. In addition academic physicians working in medical faculties and the physicians in the private sector, also contribute to the national work force. Present carder for sub-specialties includes 35 specialists in cardiology, 16 in neurology 18 in rheumatology and 12 in respiratory medicine.

\section{What is beyond 2010?}

The Ministry of Health in consultation with other stakeholders of health care delivery has developed the consultant cadres up to year 2015. The consultant physician cadre will increase up to a total of 376 by year 2015 (Figure 1). A change in the specialist cadre is highlighted in the Figure 2.

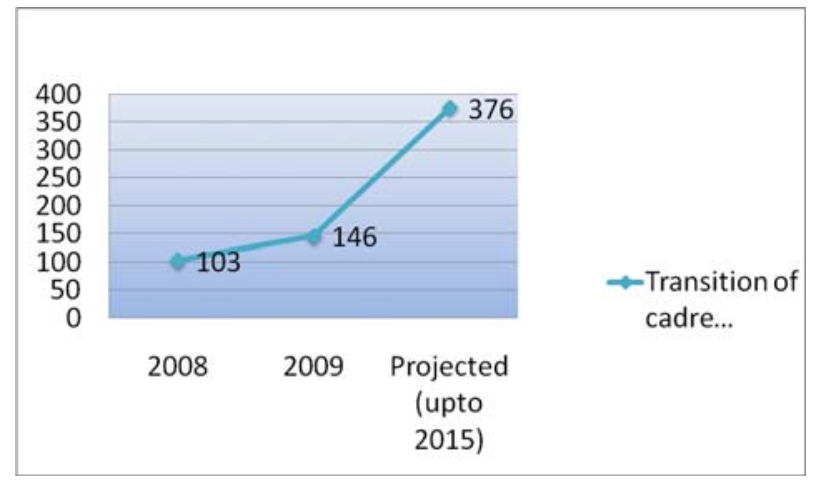

Figure 1. Physician cadre projections.

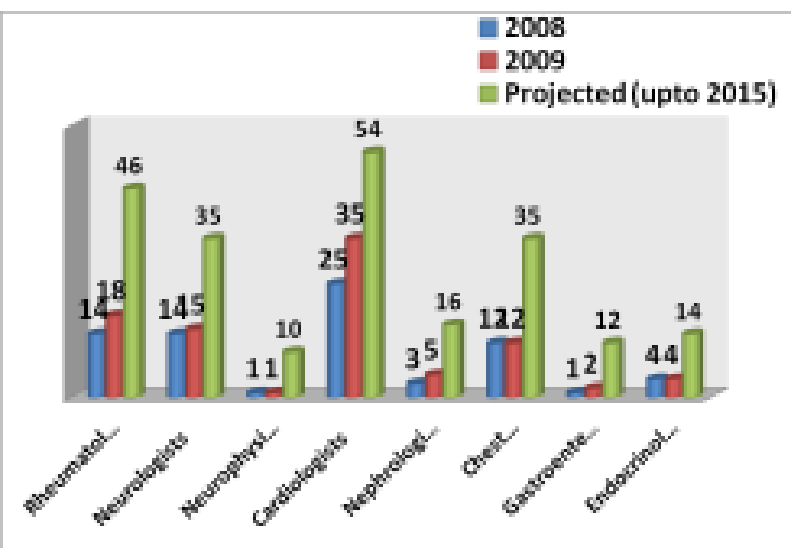

Figure 2. Projected cadre in subspecialties.

As the cadre projections for the future is known, the Ministry of Health will absorb only a given number of post MD (Medicine) trainees in a stepwise manner. For general medicine this will be 25 or less per annum. District general hospitals and base hospitals will accommodate the majority of physicians in 2015. Number of base hospitals will be upgraded to accommodate more physicians. The working conditions for the young physicians in some of these places would be quite challenging after spending long years acquiring knowledge and skills in an urban and overseas medical institutions.

\section{Therefore, the future challenges are:}

- From 2010 onwards the number of trainees that will be absorbed to the state sector will be limited.

- Beyond 2015, unless there is a rapid expansion of infrastructure development in health care institutions training opportunities will be further limited to only replacing those who retire or leave the service.

- As future training requirements are according to the needs of the country, the trainees will no longer be able select the field of their choice.

- In the next decade, the output from our medical schools will continue to increase. In addition there will be a growing number of foreign graduates who wish to join the medical work force of the country. Limiting the number of postgraduate training posts will not only create frustration among these young doctors but also will pave the way to a brain drain of the country's most intellectual individuals.

\section{Developing new specialties}

Time is opportune for us to develop new specialties as the current and future health demands cannot be met through the existing main and subspecialty arrangements.

As we have a growing elderly population, it is necessary to provide Consultants in geriatric medicine to meet their health requirements. Different models of Geriatric care should be considered when developing this specialty. The model appropriate for us is likely to be a community based and home based service rather than a hospital based or institutional based geriatric service. Our curriculum should reflect this system and we should be selecting suitable foreign training slots that would enable trainees to learn in these settings.

Critical care Medicine: We are witnessing a major trend towards system-based care delivered by multiple specialists in managing ICU patients. Critically ill patients are having increasingly complex care needs that cut across professional boundaries, requiring coordinated approaches to care. Evidence from several studies suggests improved outcomes when critical care physicians assume substantial responsibility over the care of critically ill patients. 
We should also look at other developing specialties such as acute medicine. This is a new specialty that has developed in the UK as a result of re-structuring of the admission policies. Once the patient is assessed at the A\&E department, he is sent to the acute assessment unit for rapid assessment. Decisions are made and patients are either discharged or referred for in-patient care within 24-48 hours. The closest to this is the concept of preliminary care unit in Sri Lanka. This is an area where we can open without a delay to young physicians already in service or who are already in training.

Introducing new specialties is a challenging issue. To successfully create a new specialty we should demonstrate a clear need for the new specialty and the Ministry of Health should have the inclination to create and fund the new training post. The educational establishment, the PGIM, should be able to provide the necessary teaching environment which includes trainers, educational supervisors and availability of clinical cases that will underpin a successful training programme. In other words there has to be an understanding between the key educational institution and all the service stakeholders. At the end of the day, it's about ensuring a consultant workforce that meets our patients' needs and provides the highest-quality health care possible.

\section{Physician in the health care environment}

During the last two to three decades we have witnessed much technological advancement in medicine, from new diagnostic methods to treatments of old and new diseases. The technological advancement in medicine has improved the outcome of many disease conditions. Organ transplants, prevention of genetic diseases and cures for some cancers have brought hope to many lives. What will the world of medicine be beyond 2010? Growing new cells in a laboratory will replace failing organs. Nanotechnology may provide ways of transporting drugs directly to the target cells, removing obstructions from blood vessels or protein plates from the brain cells of senile patients.

However, all this care come at a cost and is not available in our medical wards where most patients with acute illnesses are being managed. Managing acute medical illnesses in general medical wards have become a challenging issue for a physician due to the lack of basic technology such as monitoring equipment and drugs in some occasions. Underfunded health system is unable meet the current demand. In addition, developing countries have to face many barriers in their approach to technology. According to the World Health Organization, around 95\% of medical technology in developing countries is imported. Astonishingly, 50\% of equipment in these countries is not in use either due to a lack of maintenance, or lack of trained personnel. This void has a great impact on the effective provision of healthcare in developing countries.

Sadly, I have also witnessed how the tide of technological advancement has changed our way of practicing medicine. In busy, overcrowded wards we tend to rely on investigations to arrive at a diagnosis. After a brief history and clinical examination it is common practice to order a host of investigations. 'Working diagnosis' has become a thing of the past for the younger generation. Over reliance on investigation without a background of clinical diagnosis may lead to errors in diagnosis. Will this also lead to the demise of clinical acumen of physicians?

Unique to the physician is their keen interest and focus on problem solving approach to make a clinical diagnosis. After the history and examination, we critically look at the information to formulate a list of problems. This process ends by making a clinical diagnosis or a probable diagnosis. So a limited number of investigations most helpful in confirming the diagnosis can be requested. Most importantly the interpretation of results is based on the initial clinical diagnosis. This is a very important process for a clinician practicing in a resource poor setting as we have to be conscious about the cost to the patient or to the state. To remain as a diagnostician in this changing world is indeed a challenge. This is a skill we should retain and impart to the younger generation.

'Hi-tech' medicine tends to be relatively expensive, both in terms of capital and recurrent expenditure. Sri Lanka in particular, due to the limited per capita expenditure on health, is forced to ration the expensive services even if it is life saving. This inequality between technology and lack of resources has created many moral and ethical challenges to our clinical practice.

Introduction of haemodialysis for management of chronic renal failure in 1960 s brought many ethical issues in Western countries. Pioneers in haemodialysis had to face lot of resistance from authorities for using an expensive, uncomfortable treatment modality which was at that time thought to be of a limited benefit to the patient. Only the determination of physicians and the demand by the patients made it possible for the haemodialysis to survive this era. Today, maintenance haemodialysis is a success story where it has progressed to a stage where patients are having the comfort of receiving haemodialysis in their own homes in many developed countries.

Prevalence of CKD is rising in Sri Lanka. Approximately 5000 patients are in need of maintenance haemodialysis. Two state sector hospitals, NHSL and 
Teaching Hospital, Kandy and one semi government hospital, SJGH have fully pledged nephrology units. Two other units; Anuradhapura and Maligawatta are in the development stage. Colombo South, Galle, Kurunegala, Ampara and Jaffna hospitals have limited facilities where they concentrate mainly on patients with acute renal failure.

I shall attempt to illustrate the dilemmas faced by patients and clinicians in this regard with a patient's story:

\section{Patient 1}

This is yet another day for Alwis at the Dialysis Unit at Colombo South Teaching Hospital which is like a second home to him. He is invariably there twice a week. At the first sight he looks like any other person of his age. But as one takes a closer look what is visible is a young man with anxious eyes, dusky skin and a fistula in his left arm. Fifteen minutes in conversation with him reveals the tragic story of how he struggled to survive with his illness, chronic renal failure. His underlying disease condition called Takayasu's disease prevents him undergoing a renal transplantation.

No disease has raised as many ethical questions as CRF for the present day physician. The physicians' moral principle to respect patients' right to treatment (autonomy) and acting on the interest of patient (beneficence) is in conflict with the lack of resources; in this case inadequacy of dialysis facilities. This situation has forced patients to travel the country looking for a unit where they will be accepted or fall in line with conservative management.

A K Maynard referred to this situation as 'Resource allocation has to deal with painful decisions of who will die and who will live; and scarce resources have to be used selectively to maximize duration and quality of life' (Role of health economics in evaluating cost-effective alternatives to hospital care. Hospital to Home Symposium.1986).

Due to the pressure from the physicians, nephrologists, patient care groups and community, management of renal failure became an issue being addressed at the national level. Plans to increase dialysis facilities in the state sector are underway, but this alone may not solve the problem. Establishment of nurse run dialysis services in the community for subsidised rates and increasing the facilities for renal transplant are the other options to be addressed. I hope the developments in nephrology services in Sri Lanka will be able to find solutions to this problem. Our contribution as physicians is to address and implement the preventive measures that would reduce the national burden of CRF.
It is inevitable for the medical profession to face many ethical challenges and dilemmas in day to day practice. The purpose of medical ethics is to protect and defend human dignity and patient's rights. Medical ethics is not only avoiding harm to the patient, but a set of norms, values and principles. The values commonly applied in medical ethics are autonomy (patient's right to choose or refuse the treatment), beneficence (doctor acting on the best interest of the patient), non-maleficence (first, do no harm), distributive justice (distribution of scarce health resources). The concept of informed consent came in to practice after the Nuremberg trial and famous Tuskegee Syphilis Study. These principles may not give answers to all the problems, but provide a useful framework for understanding conflicts and providing answers.

\section{Physician as a teacher}

\section{a) Undergraduate Medical Education}

The American Mission School at Manipay was the first local medical school in Sri lanka. In 1870 the Colombo Medical School was started in a building in the General Hospital. It was later moved to its present location and named as Faculty of Medicine when it was incorporated into the university system. The second medical college was established in Peradeniya in 1962, followed by two other faculties in Jaffna and Ruhuna. Today we have 8 medical faculties in the country with a student intake exceeding 1000 per annum.

The traditional approach to medical education was teacher-centered and the main method of imparting the knowledge was by lectures. Clinical teaching emphasised physician authority and deemphasised patient autonomy. A change in the strategies of medical education was felt to be necessary to meet the complex requirements demanded by the changing clinical environment and patient expectations. We need to equip the undergraduates and postgraduate trainees the ability to practice medicine in a changing new world and to be lifelong learners.

The way medicine is taught has changed drastically over the last two decades. Medical schools have changed their curricula to accommodate more student centered approach compared to teacher centered approach. More emphasis is given on communication skills, ethics and professional development. Community based training models are introduced in to the teaching to gain an insight into the social aspects of health care. Computer laboratories provide students easy access to information. Facilities are available to teach clinical skills in the classroom using simulators and mannequins. Learning research methodology and fostering research skills is now an integral part of the medical curriculum. 
Will all these developments undermine the value of bedside teaching where the clinicians play a major role? Sir William Osler (1849-1920), a renowned clinician and teacher stressed the importance of teaching at the bedside. In 1903 he stated,"How can we make the work of the student...practical...? The answer is, take him from the lecture room, take him from the amphitheater - put him in the outpatient department - put him in the wards".

What are the views of the medical students? The feedback from our final year students shows that they see the bedside as an excellent place to learn a wide variety of clinical conditions and skills and often request more beside teaching sessions.

Why do we value bedside teaching? This is where the students learn how to take a clinical history, how to carry out a physical examination, critically evaluate the information they gather and formulate a diagnosis and a sound management plan. Bedside provides the opportunity to teach humanistic aspect of clinical medicine and role modeling of professional behaviours which cannot be accomplished in the class room. It is also through bedside teaching the students learn about their patient's life, values and develop personal relationship and mutual trust with the patient.

Despite its importance, bedside teaching appears to be in decline. Most physicians have a role in teaching. Physicians are expected to accommodate teaching within their busy daily schedules. It is obvious that the changes in the health care environment have created barriers that limit the clinical teachers' time that is spent on bedside teaching. Overcrowding of wards, admission policies of hospitals, pressure to see more patients in clinics and time spent on administrative matters are some issues. Bigger student groups and a lack of recognition by the relevant authorities may be other issues that have an impact on clinical teaching. How do we improve on this very effective teaching method? Barriers to bedside teaching need to be defined clearly and methods to overcome them should be addressed. This responsi-bility should be taken by the academic physicians.

\section{b) Postgraduate medical education}

Postgraduate medical education in Sri Lanka has evolved through several stages. In the post colonial era, foreign qualifications were considered as the requirement for the specialist status. The system they were trained did not give them the competency to address the diseases that were prevalent in our country. Many who went overseas either at state expenses or on paid leave did not return back to the country. There was no system for supervised training after MD or MRCP and they were directly appointed as hospital consultants.
As the need for the local postgraduate training became obvious, the Postgraduate Institute of Medicine was established in 1976 on the recommendations of an advisory committee on higher education. In 1980 the regulations were changed to accept the qualifications offered by the PGIM for the employment of consultants in the state sector of the island. A new era of medical education was born.

Postgraduate medical education differs from undergraduate education in several aspects. The trainee is expected to combine intensive learning and developing clinical skills with a provision of service.

The postgraduate training is mostly work based training which is defined as 'learning for work, learning at work and learning from work'. This may be supplemented by learning activities such as mortality morbidity meetings, journal club meetings and case presentations. Clinical supervision appears to be informal. The trainees face an in-service assessment and appraisal during their training but the value of such assessment is yet to be validated. Training programme is not subjected to external review or quality control.

Training is purely by clinicians attached to the main teaching hospitals who have primary responsibility for patient care and responsibilities of their units and hospitals. Trainees will have to deal with their clinical commitments and out-of-hour duties which give them inadequate time for self learning. It is quite possible that the objectives of the training to be lost or forgotten by both parties due to their heavy service commitments.

Therefore, the challenging issues in postgraduate education are,

- How do we optimize the training in a highly pressured working environment?

- Do they have adequate facilities for learning? e.g. library and internet facilities

- Do the trainers have adequate time for learning?

- Are the trainers aware of the training requirements?

- Do we use trainee feedback to improve our teaching strategies?

- Is there enough flexibility within the programme to carry out research activities of their choice?

Our challenge in the 21st century is to produce an efficient and a compassionate physician for tomorrow. They should be able to meet the local needs as well as suit the global requirements. To achieve this excellence in postgraduate medical education, 
'training the trainer' or faculty development has become a pressing need in many countries of the world. Challenges to faculty development are said to be unique to most countries. They are mainly the constraints for funding and lack of time for the clinicians to attend such training, and lack of motivation of the trainers.

\section{Physician as a researcher}

We live and work in an evidence-based medicine era. The physician has to rely on the research findings to provide effective and safe treatment to his patients. There is no specific data for medical research available to Sri Lanka. However, overall research output stands very low. In 2006 Sri Lanka's research and development expenditure was $0.2 \%$ of GDP and that of India 1.1\%, Pakistan $0.3 \%$ and Nepal 0.2\%. EastAsian countries invest $1.5-2.5 \%$ of GDP on research and development.

Research output measured by international publications/Science Citation Index (source National Research Council)

\section{1}

Sri Lanka

133

Pakistan 399

India

Singapore

10468

USA

658

224,955
2006

Sri Lanka

204

Pakistan

877

India

20705

Singapore

5438

USA

303,011
Even though $80 \%$ of global disease burden is in developing countries, the proportion of research conducted in these countries is less than 10 per cent of the global research activity. The obstacles to biomedical and health care research in developing countries are complex and often poorly understood. From the Sri Lankan point of view, lack of training in research, lack of appreciation of research for career progress, shortage of funding, limited access to health care information, certain concerns on ethics are the main reasons that hinders progress in research. Unfortunately we have failed to attract young scientists who have trained abroad due to many draw backs in the existing system.

How do we build up a research culture within our profession? We should give priority to teaching of research methodology and skills in the undergraduate, postgraduate continuous medical education programmes. Incorporating clinical research in to the Senior Registrar training is commendable. Professional associations should take a leading role in incorporating research in to their CME programmes. We should develop our own research agenda that will address the national requirements. Basic knowledge in research skills is of paramount importance to critically evaluate the medical literature and to put research evidence into practice. Physicians should grab this opportunity to teach younger generation on critical evaluation of research by organising journal clubs, and during case presentations as currently happening in some teaching institutions.

\section{Physician in the society}

Buddhist philosophy on eliminating suffering parallels with the objectives of medicine. The care of the sick has been emphasised in Buddhist teaching and according to the Vinaya pitakaya, the Buddha himself stated "Whoever, O monks, would nurse me, he should nurse the sick". Buddhist monks and followers have been involved with the care of the sick for over two thousand years.

Expectations of a society to a large extent depend on the traditions and values of people. Art of healing was valued in high esteem by the ancient Sri Lankan society which was nurtured on Buddhist philosophy. Doctor was allotted a high place in the society. It was accepted that the physician authority is of paramount importance in taking decisions to save the lives of patients. Most saw it as a profession that can cause miracles especially at times of epidemics such as malaria. Few people questioned the authority of doctors. Even in western countries the same situation prevailed in 1950s.

Both sociologists and physicians themselves were involved in research to understand the public perception on physicians' role. In 1992, a nationwide survey in USA asked the respondents about their opinion on following competencies of a physician; diagnosis and treatment of an illness, communicating with a patient, ethical practice, cooperating with other health care professionals, disease prevention, using technology correctly and consideration of cost to the patient. While all these competencies were rated as important three competencies namely, diagnosis and treatment, communication and ethical conduct received highest ratings. Although respondents were of the opinion that the communication is one of the most important skills a physician to have, they rated their own physician lowest on the communication skill compared to other skills.

These and other research findings made the professional organizations to address the issue on improving doctor-patient relationship. These findings also had implications on medical education. The last three decades we have witnessed the global trend in changing the medical practice from 'physician-centered medicine' to 'patient centered medicine' which means the physician no longer takes judgments on his own regarding patient care. Instead what patient needs 
assumes importance and decisions are reached by involvement of both parties. This is referred to as patient autonomy or shared-care. The studies clearly demonstrates that the medical outcomes are best when patients are fully informed and involved in the decision making process.

Sri Lankan community is slowly changing its attitude from traditional emphasis of physician-centered medicine to patient centered medicine. Still in our culture, most patients are reluctant to engage in the decision making process. Unlike western societies, access to information via internet and other sources are limited to the majority. Therefore, it is our responsibility and challenge to become better communicators and respect patients' rights. Let us remember that our patients have the right to humane treatment, right to information, consent, privacy and confidentiality. They have the right to complain and compensation and right to preventive measures.

Ladies and gentlemen,

This evening we have seen a glimpse of the challenges we are facing in a changing world. We have seen how the profession is growing slowly achieving its own goals. The motto of our College is Arogyam, Shantham, Sukam; cure, relief and comfort. Let us carry them always in the forefront while achieving our common goal of providing timely and quality care for our patients. 